\title{
Project managers' overconfidence: how is risk reflected in anticipated project success?
}

\author{
Golo Fabricius ${ }^{1} \cdot$ Marion Büttgen $^{1}$
}

Received: 6 July 2014/Accepted: 29 July 2015/Published online: 7 August 2015

(C) The Author(s) 2015. This article is published with open access at Springerlink.com

\begin{abstract}
Projects tend to exceed planned timelines and budgets. One reason may be that potential project risks are insufficiently reflected in anticipations of project success. Furthermore, project managers' overconfidence may lead them to assess risk in a biased manner. The present study examines how risk assessment relates to overall anticipated project success and how overconfidence on the part of project managers influences such assessments. We assume that project managers' risk awareness serves as a mediator between overconfidence and risk assessment. To observe the planning behavior of 204 project managers, we used a standardized, case-based survey. The results show that overconfidence reduces risk awareness among project managers, leading them to assess risks more optimistically and come to more positive conclusions about anticipated project success. When judging project success, project managers only consider the probability of a risk occurring; they do not factor in the impact of said risks on project success should the risks arise. Risks thus seem to be insufficiently reflected in anticipations of project success which might be a reason for high failure rates of projects.
\end{abstract}

Keywords Project management $\cdot$ Overconfidence $\cdot$ Risk analysis $\cdot$ Risk awareness · Project success

We thank the GPM Deutsche Gesellschaft für Projektmanagement e.V. (German Association for Project Management) for their valuable support in conducting this survey and Gena Olson for her helpful comments.

Golo Fabricius

golo.fabricius@uni-hohenheim.de

Marion Büttgen

m.buettgen@uni-hohenheim.de

1 Institute for Marketing \& Management, Universität Hohenheim, Schloss Osthof/Ost (570 B), 70593 Stuttgart, Germany 
JEL Classification A12 $\cdot$ D81 $\cdot$ D84 $\cdot$ L21 $\cdot$ L26

\section{Introduction}

The Berlin-Brandenburg Airport was originally budgeted at nearly 2 billion euros (Press Release Airport Berlin-Brandenburg 2004), but the project ran into deadline troubles and the total costs will exceed twice the projected amount (Handelsblatt 2015). Unfortunately, this project is no isolated incident. When it comes to project management, countless examples demonstrate the human tendency to set overly optimistic plans (Buehler et al. 1994; Pich et al. 2002; Raz et al. 2002), both in the public and private sector (Huff and Prybutok 2008; Shepherd and Cardon 2009; Whittaker 1999). However, due to the complexity inherent to many projects, it often remains difficult to determine the reasons for even obvious cases of overly optimistic project planning.

We focus on project managers' risk assessment to evaluate potential reasons for poor project performance. Risks are inherent in every project (Huff and Prybutok 2008) and defined as uncertain events that exert positive or negative effects on a project's objectives (Bryde and Volm 2009; PMI 2008), making risks a likely reason for deviations from the project management plan. Various studies have found that project risk management measures, including assessing the impacts of risks and the probability of them occurring, are key contributors to project success (Oehmen et al. 2014; Raz et al. 2002; Salomo et al. 2007; Teller et al. 2014). What has not been investigated, however, is how risk assessment influences project managers' anticipated project success. Many projects may fail to achieve project objectives as a result of risks being insufficiently considered by project managers, thus leading them to make overly positive projections for project success. To the best of our knowledge, no management studies have focused on how project managers' risk assessment may not adequately be considered in their anticipated project success. Risk assessment includes the evaluation of the impacts of risks and the probability of them occurring. The present study investigates whether both impacts and occurrence probabilities of risks are considered in project managers' anticipations of project success. These risk assessments may, in addition, be affected by overconfident judgments, as people are often unaware of the limited accuracy of their judgments and tend to express overly high levels of confidence in their ability to make accurate estimates (Moore and Healy 2008). This bias is referred to as overconfidence and has been found to lead to risky behavior in various business settings such as entrepreneurial decision making (Hayward et al. 2006), investment decisions (Nosić and Weber 2010), or new product development (Simon and Houghton 2003). While the literature shows that overconfidence may promote risk taking, it remains unclear what links overconfidence to risky behavior.

Prior to demonstrating risky behavior, people must first engage in a decisionmaking process in which they assess potential risks and subsequently choose their behavior (Glöckner and Betsch 2008; Tversky and Kahneman 1992). Aiming to clarify the cognitive process between risky behavior and overconfidence, we evaluate how overconfidence influences the assessment of risks. Risk assessment is 
an antecedent of risky behavior and has been shown to predict such behavior (Cooper and Faseruk 2011; Glöckner and Betsch 2008). With risk assessment, we evaluate a hitherto neglected link between overconfidence and risky behavior. In reference to the availability of risks in memory (Tversky and Kahneman 1973), we furthermore introduce risk awareness as a mediator between overconfidence and risk assessment and define risk awareness as the generic attitude of people toward the threat which risks pose. The present study investigates how overconfidence may reduce risk awareness and lead to an overly optimistic risk assessment, thereby clarifying how overconfidence may lead to risky behavior.

We base our research on a case study, which we conducted with 204 professional project managers. Our case study simulated the planning process for a product development project, including a work breakdown structure, milestone schedule, quantitative risk analysis, and assessment of anticipated project success. We also gathered data on participants' overconfidence, risk awareness, and demographic profiles. The evaluation of the study was conducted using SmartPLS (Ringle et al. 2005).

The results indicate that risk assessment is influenced by project managers' overconfidence through the mediator of risk awareness. Additionally, risks seem to be insufficiently reflected in project managers' anticipated project success. Thus, our study offers the following contributions: Firstly, the present study considers the process through which overconfidence may lead to risky behavior, while earlier research mostly links overconfidence directly to risky behavior (Li and Tang 2010; Nosić and Weber 2010; Simon and Houghton 2003): Overconfidence leads to a lower perceived threat of risks (i.e., lower risk awareness), which in turn influences project managers' risk assessment. Secondly, risks are insufficiently considered in anticipated project success: Only the estimated likelihood of a risk occurring has an influence on a project manager's assessment of project success; the estimated impacts of these risks are neglected. This may lead to overly positive anticipated project success, as risks with a high impact on project outcomes are insufficiently considered. Insufficient consideration of risks results in the project deviating from anticipated outcomes, which may be a reason for the common high failure rates in project management. Thirdly, from the perspective of decision theory, the lack of influence that estimated risk impact has on anticipated project success is unexpected, as decision theory suggests that people focus on outcomes, which are directly affected by risk impacts, before considering probabilities (Brandstätter et al. 2006; Brandstätter and Gussmack 2013) or at least consider outcomes and probabilities to a similar extent (Glöckner and Betsch 2008; Tversky and Kahneman 1992). Our study therefore offers valuable insights into how risks are considered when anticipating success.

The body of this article is structured as follows: First, we elaborate the research background and discuss our research model as well as the associated hypotheses. Second, we describe our study procedure and the measures that were used. Third, we present the results of our study, followed by a discussion including conclusions and implications of our findings. 


\section{Research background and hypotheses}

\subsection{Risk assessment and anticipated project success}

Failed projects are a major topic in academia (Shepherd et al. 2011) as well as in project management magazines, blogs, and mass media (Huff and Prybutok 2008). Most experienced project managers are likely to have first hand experience with failed projects or missed targets, due to the occurrence of risks which impact project outcomes (Jugdev and Müller 2005; Raz et al. 2002). Nevertheless, when starting projects with the goal to, for instance, optimize internal processes or create competitive advantage through innovative product development, risk taking is an inevitable prerequisite for achieving company goals (Brockman et al. 2012), as there is no such thing as a risk free project (Huff and Prybutok 2008). It is widely acknowledged in project management literature that risks may have positive or negative effects on a project's objectives (Bryde and Volm 2009; Maguire and Hardy 2013; PMI 2008) and therefore may not only be a threat to project success, but also create opportunities (Teller et al. 2014). However, project risk management processes still focus on potential negative effects (Bryde and Volm 2009; Raz et al. 2002), and risks in a project management context usually refer to uncertain events with negative or undesirable consequences (Maguire and Hardy 2013; Oehmen et al. 2014). Thus, it can be concluded that project risk management aims to identify uncertain events and their (predominantly negative) impact on the project for the purpose of reducing the said impact (Pich et al. 2002). Theories which seek to explain decision making under uncertainty are the priority heuristic (Brandstätter et al. 2006; Brandstätter and Gussmack 2013) or expected utility models such as the (cumulative) prospect theory (Kahneman and Tversky 1979; Tversky and Kahneman 1992). When determining the utility of implementing a project by using expected utility models or assessing the choice to implement a specific project by using the priority heuristic (Brandstätter et al. 2006; Glöckner and Betsch 2008), the decision to implement said project will depend on the impact that risks will have on the outcome of the project and on the probabilities of these risks occurring. The assessment of risks therefore forms the input of the decision process which decision makers follow when deciding on the implementation of a project.

Literature offers two heuristics as possible mechanisms underlying risk assessment: availability heuristic and affect heuristic (Pachur et al. 2012). Availability heuristic proposes that people assess the probability of an event by the ease with which occurrences of similar events can be recalled (Schwarz et al. 1991; Tversky and Kahneman 1973). The availability of risks has been confirmed to highly correlate with people's judgments of risk occurrence probabilities (Hertwig et al. 2005; Pachur et al. 2012). When risks occur, they can evoke strong emotions (Pachur et al. 2012). The affect heuristic (Finucane et al. 2000; King and Slovic 2014; Slovic et al. 2007) focuses on this linkage between risks and emotions, proposing that people use their affective, emotional response to a risk to judge its impact and occurrence probability. Pachur et al. (2012) compare how well availability heuristic and affect heuristic predict people's judgments and find that 
overall availability of direct experience seems to be a better predictor than affective information. However, their results furthermore indicate that people do not exclusively rely on one heuristic, but combine both heuristics, either sequentially or in a composite fashion (Pachur et al. 2012). Therefore, people's risk assessment is likely influenced by both availability of risks and the affective, emotional response to risks.

Risk assessment in project management is carried out by quantitative risk analysis, which is a central part of risk management (Raz et al. 2002; Teller et al. 2014). Quantitative risk analysis is defined as "the process of numerically analyzing the effect of identified risks on overall project objectives" (PMI 2008, 294). It involves the assessment of the estimated probability of a risk occurring and the estimated impact that the risk's occurrence would have on project objectives. Raz et al. (2002) assess the usage of five risk management practices, including risk assessment in terms of estimated risk occurrence probability and estimated risk impact, and find that the usage of these risk management practices contributes to meeting budget goals in projects characterized by high uncertainty. Teller et al. (2014) and Salomo et al. (2007) find that the application of formal project risk management leads to higher project portfolio success. Likewise, Oehmen et al. (2014) find that risk management practices, including the quantification of expected impacts of risks on main project objectives, or the systematic monitoring and reviewing of risks, positively influence decision-making quality, the stable execution of the project plan, and a proactive project organization. Furthermore, their findings indicate that applying risk management practices indirectly influence both project success and product success (in the context of new product development) mediated through the aforementioned constructs of decision-making quality, stable project plan execution, and a proactive project organization.

Despite the considerable amount of research conducted on project success, no consensus has yet been reached regarding the definition of project success and project failure (Ika 2009). Project success is a multi-dimensional construct of compliance with overall project objectives (Jugdev and Müller 2005), with different dimensions having been suggested as essentials (Ika 2009). The classic solution upon which most researchers can agree is to apply the "triangle of virtue" as success criteria: time, costs and quality (Ika 2009; Raz et al. 2002). We define project success as the compliance of the project's outcome with what is specified in the project plan regarding time, costs, and quality. In the present study, the anticipated project success is measured by assessing the project managers' expectations of future project success. We consider anticipated project success to be a relevant measure in our model, as decision makers and project managers are likely to base their decision to begin or to continue a project on how successful they anticipate the project to be. After introducing the research background of risk assessment in project management and the concept of project success, we now move to the concept of overconfidence seeking to explain why project managers' risk assessment may be overly positive. 


\subsection{Overconfidence}

A cognitive bias which has often been linked to risky behavior is overconfidence (Hayward et al. 2006; Li and Tang 2010; Nosić and Weber 2010): People tend to be too certain about the accuracy of their own estimates, a general tendency that has been well documented in academic literature (Pulford and Colman 1997; Teigen and Jørgensen 2005; Tsai et al. 2008). In the present study, we adopted a narrower definition of overconfidence as an overestimation of one's own ability to make accurate estimates (Moore and Healy 2008, also referred to as "overprecision"). Overconfidence has been discussed as the cause of entrepreneurs founding new companies even when the prospects of success are dim (Hayward et al. 2006). Busenitz and Barney (1997) argue that without biases such as overconfidence, many entrepreneurial decisions would never be made and show that entrepreneurs are significantly more overconfident than managers in large organization.

Despite these potentially favorable effects of overconfidence in entrepreneurship, overconfidence has been shown to lead to hazardous risk taking, lowering the performance of investment portfolios (Barber and Odean 2001), and leading people to invest in riskier portfolios (Nosić and Weber 2010). Overconfidence also relates positively to the degree of risk linked to a product introduction in the way that decision makers who decide on riskier new product introductions exhibit higher degrees of overconfidence (Simon and Houghton 2003). Similarly, Li and Tang (2010) find that risk taking of a company relates positively to the CEO's overconfidence, leading CEOs to overpay for target companies and to undertake value-destroying mergers (Malmendier and Tate 2008). Not even specialists and experts are immune to overconfidence: McKenzie et al. (2008) find similar levels of overconfidence among groups of IT experts and students. Similarly, Speirs-Bridge et al. (2010) identify overconfidence among health-care specialists and environmental experts, and Jørgensen (2004) notes overconfidence expressed by IT professionals.

After we now introduced the research background of our study, we will, based on already identified research gaps and research questions, develop our hypotheses in the following section.

\subsection{Hypothesis development}

People use heuristics ("rules of thumb"; Hutchinson and Gigerenzer 2005) to assess situations or make decisions when it is not possible or efficient to consider all potentially available information. As most of the time not all potentially available information is considered, heuristics are applied in most decisions to simplify decision making (Busenitz and Barney 1997). Heuristics are useful when predicting future developments (Gigerenzer and Brighton 2009). Where simple and valid feedback exists and people have the opportunity to learn from this feedback, judgments based on heuristics will on average be more accurate than analytical judgments (Bingham and Eisenhardt 2011). When, however, the environment of decision making is characterized by high complexity and dynamic feedback-as is 
the case in project management (Pich et al. 2002) —intuitive judgments that are based on heuristics may lead to systematic biases (Kahneman and Tversky 1996).

According to the priority heuristic (Brandstätter et al. 2006), people base their decision first on potential outcomes of the decision and second on respective probabilities of these outcomes (Brandstätter and Gussmack 2013). While assessing both the impacts of risks and the probability of them occurring contributes to project success (Oehmen et al. 2014; Raz et al. 2002; Salomo et al. 2007; Teller et al. 2014), it has not been investigated how risk assessment is considered in anticipations of project success. We propose that many projects may fail to achieve project objectives as a result of risks being insufficiently considered by project managers, thus leading them to make overly positive projections for project success.

When they occur, risks have an impact on project costs and project completion time (Marmier et al. 2013); so, anticipated project success should depend on estimated risk impacts, as well as on estimated occurrence probabilities. The risks we consider in this study all have negative or undesirable consequences for the focal project, in line with standard project management practice (Maguire and Hardy 2013; Oehmen et al. 2014). The outcomes that result from the decision to carry out the project are always influenced by occurring risks (Raz et al. 2002), such that increasing risk impacts and risk occurrence probabilities mitigate the value of the decision to conduct the project (Dey 2012). If project success is compliance with a specific outcome, which has specific value to the company, then anticipated project success should decrease with greater risk impacts and risk occurrence probabilities.

Thus, we hypothesize:

H1a Project managers who consider project-related risks more likely anticipate lower project success.

$\mathrm{H} 1 \mathrm{~b}$ Project managers who expect project-related risks to have a stronger impact on project goals anticipate lower project success.

Anticipation of success is prone to biases linked to the desirability of the outcome (Seybert and Bloomfield 2009; Vosgerau 2010; Windschitl et al. 2010) or to perceived but non-existent control over the outcome (Goodman and Irwin 2006; Langer and Roth 1975). At the same time, information supporting desirable outcomes is perceived to be more credible than information supporting undesirable outcomes (Barber et al. 2009; Gordon et al. 2005). In this sense, anticipated project success may be biased by people's insufficient consideration of the impact or occurrence probability of risk. An insufficient consideration of risk will lead to deviations between anticipated and actual project success, which results in higher project failure rates. Expected utility models such as prospect theory (Kahneman and Tversky 1979; Tversky and Kahneman 1992) or more simple expectancy value models such as the expected monetary value analysis, which is commonly applied in project management (Dey 2012; PMI 2008), would predict that both risk occurrence probabilities and risk impacts have a similar influence on the decision to carry out a project. However, Brandstätter et al. (2006) suggest in their priority heuristic that people do not base their decisions on internal calculations of occurrence probability and related outcomes, but focus primarily on outcomes before considering 
probabilities (Brandstätter et al. 2006; Brandstätter and Gussmack 2013; Glöckner and Betsch 2008). Applying this prediction to a project management context, we anticipate that the impact of risk impact on project success $(\mathrm{H} 1 \mathrm{~b})$ is the primary path of influence, while risk occurrence probability (H1a) influences anticipated project success less powerfully. Thus we propose $\mathrm{H} 2$ :

$\mathrm{H} 2$ The influence of the estimated risk impact on anticipated project success is stronger than the influence of the estimated risk occurrence probability on anticipated project success.

While earlier research mostly links overconfidence directly to risky behavior (Li and Tang 2010; Nosić and Weber 2010; Simon and Houghton 2003), decision theory suggests that people must first engage in a decision-making process in which they assess potential risks and subsequently choose their behavior (Glöckner and Betsch 2008; Tversky and Kahneman 1992). In the following, we investigate how overconfidence may reduce risk awareness and lead to an overly optimistic risk assessment. Thereby we aim to clarify how overconfidence may lead to risky behavior.

In general, people tend to imagine positive outcomes for their plans, overwhelmingly ignoring possible negative scenarios in favor of wishful thinking (Newby-Clark et al. 2000). In a project planning context, this tendency implies that project managers mostly work under the assumption that all their projects will succeed (Raz et al. 2002), with the apparent belief that project risks will not occur or will have little impact on the project's success. An overconfident project manager is overly certain that his or her predictions are correct (Moore and Healy 2008) and thus will consider it unlikely that reality will deviate from her or his plans. Overconfident decision makers underestimate the variance of the result they are trying to predict (Moore and Healy 2008). Therefore, an overconfident individual will likely only generate a single or a very limited number of scenarios when assessing uncertain future developments and will typically focus on how objectives will be accomplished successfully (Newby-Clark et al. 2000). This implies that scenarios which contain the occurrence of risks will not be readily available in project managers' minds. Van Zant and Moore (2013) refer to such low availability when they state that overconfidence can blind people to the size of the risks they are taking. According to the availability heuristic (Schwarz et al. 1991; Tversky and Kahneman 1973), a low availability of incidents in which risks occurred will lead to lower estimated risk occurrence probabilities (Sjöberg and Engelberg 2010) and may cause risks to be perceived as less threatening (Pachur et al. 2012). We propose that overconfidence is linked to low availability of incidents in which risks occur, leading to lower risk awareness. We hypothesize that overconfidence willmediated through risk awareness-lead to lower estimated risk occurrence probabilities and estimated risk impacts:

H3a Higher overconfidence leads to lower estimated risk occurrence probability through the mediation of risk awareness.

$\mathrm{H} 3 \mathrm{~b}$ Higher overconfidence leads to lower estimated risk impact through the mediation of risk awareness. 


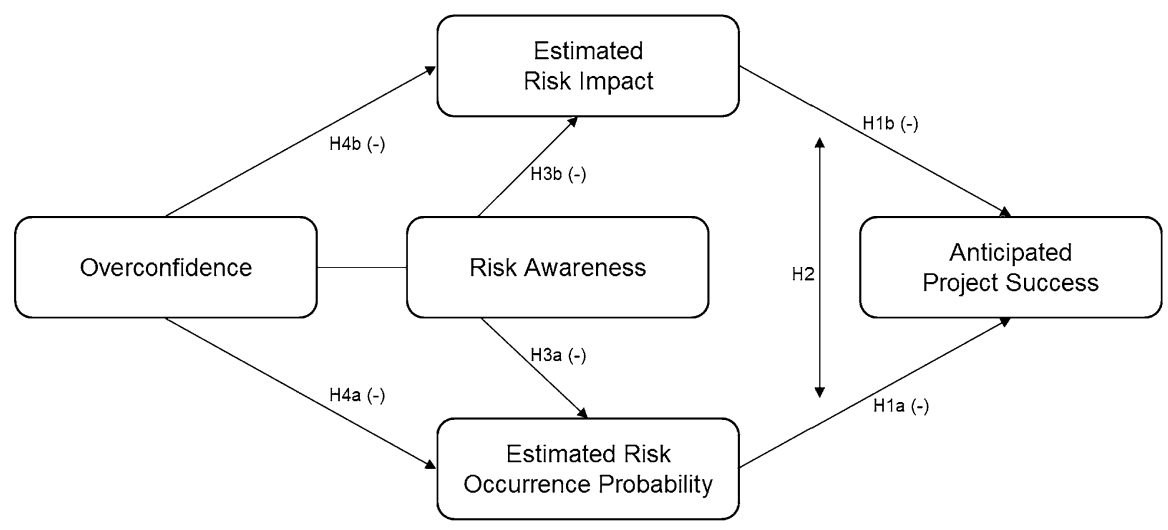

Fig. 1 Research model

Apart from the hypothesized impact of overconfidence on risk assessment through the mediator of risk awareness, we furthermore assume that overconfidence might be linked directly to an overly positive assessment of risk occurrence probabilities and risk impacts. Overconfidence has been shown to lead to hazardous risk taking by overtrading stocks, decreasing portfolio performance compared to market performance (Barber and Odean 2001) and leading people to take additional risks (Van Zant and Moore 2013). Similarly, overconfidence leads CEOs to overpay for target companies and to undertake value-destroying mergers (Malmendier and Tate 2008). CEO's overconfidence furthermore leads to increased risk taking by the firm ( $\mathrm{Li}$ and Tang 2010). Because decision theory suggests that people assess risks before they engage in risky behavior (Glöckner and Betsch 2008), we predict that higher overconfidence leads to more positive risk assessments:

$\mathrm{H} 4 \mathrm{a}$ Project managers with greater overconfidence consider project-related risks less likely.

$\mathrm{H} 4 \mathrm{~b}$ Project managers with greater overconfidence expect project-related risks to have less impact.

Our research model is in Fig. 1.

\section{Method}

\subsection{Sample characteristics}

A total of 204 project managers from different companies and industries took part in this study. Most of the participants $(89 \%)$ had at least 3 years' experience in project management; nearly half (47\%) had more than ten. The most common age range was 36-45 years $(43.1 \%)$. Furthermore, $55.4 \%$ of participants had certification in project management, and a further $7.4 \%$ planned to obtain one. $78.0 \%$ had a 
university degree; $8.8 \%$ had attained a doctoral degree. Finally, $18.1 \%$ of participants were women and $81.9 \%$ were men.

\subsection{Procedure}

Participants received a survey to be completed online. A case study simulated the planning process of a product development project, including a work breakdown structure, a milestone schedule, a quantitative risk analysis, and an assessment of anticipated project success in terms of time, costs, and quality. We subsequently measured participants' overconfidence and risk awareness along with their demographic data. The online survey took an average (mean) of $18 \mathrm{~min}$ per participant to complete.

During the development of the case study, we consulted experienced project managers to discuss potential difficulties in understanding and to ensure that the case study mirrored project management practice. At the end of the survey, participants were asked to leave anonymous remarks in a textbox. These remarks were generally quite positive and did not indicate any difficulties in understanding the survey, nor did the participants criticize the planning instruments used in the study.

\subsection{Case study and work breakdown structure}

The case study scenario described a fictional company that produces wooden toys for children and wants to develop a new toy. For the survey, the participant assumed the role of a project manager who would oversee product development. Participants received a description of the requirements for the new product, as well as pictures of similar products already in the company's product portfolio. We also provided them with information about the company's production processes, other parties involved in the project, and a monetary budget.

After reviewing the project's background information, participants familiarized themselves with the tasks that needed to be accomplished to conduct the project. The project managers dragged and dropped six predefined work packages (Appendix Fig. 3) into a work breakdown structure, divided into four sections. The work breakdown structure was not a measurement instrument, but was rather intended to help participants become familiar with the project and associated tasks. No deadline or budget planning was involved in this step.

In the following step, after participants familiarized themselves with the project structure, they created a milestone schedule to plan the project completion time. After sorting all tasks (known from the work breakdown structure) into the four phases of the project milestone schedule, project managers estimated how many weeks each phase of the project would take. The project was considered complete if all phases in the milestone schedule had been completed. The cumulative estimated duration of all phases, i.e., the estimated completion time of the project, served as preparation for the measure of anticipated project success. 


\subsection{Assessments and measures}

\subsubsection{Anticipated project success}

The assessment of anticipated project success includes individual ratings of time, costs, and quality. For example, we asked about the likelihood of a project "not going over the amount allotted in its budget". Project managers made their assessments on a seven-point Likert scale ( $1=$ highly unlikely; $7=$ highly likely). The budget and given time frame for the project were indicated, as conformance with project goals can only be measured relative to a specification (Karmarkar and Pitbladdo 1997).

Defining project success in terms of time, costs, and quality is not only easily applicable and understandable, but also widespread in project management practice (Jugdev and Müller 2005). Measurement approaches that take a broader scope on critical success metrics may be more sophisticated from a theoretical point of view, but are rarely confirmed by credible empirical research (Nicolai and Kieser 2002). Accordingly, we chose to limit ourselves to the well-established fundamentals. Anticipated project success contains several dimensions, making it a formative measure. Multicollinearity was not present, as the maximum VIF of all items was 3.1 .

\subsubsection{Risk assessment: risk occurrence probability and risk impact}

Risk assessment includes both the assessment of the likelihood that a risk will occur and the assessment of the risk's impact on the project should the said risk actually occur (Raz et al. 2002; Teller et al. 2014). Risk assessment was conducted in the context of the case study using predefined risks. For example, participants estimated the occurrence probability and risk impact on the project for the following risk: "The design of the product has to be changed in order to ensure technical feasibility". Each risk was accompanied by background information that explained the situation and previous similar experiences, usually mentioning relevant quantifiable facts (see Appendix Fig. 4). For the aforementioned risk, the following background information was provided: "Over the past several years, around $40 \%$ of all newly developed products had to be changed in order to fit technical requirements. For instance, designs are changed when the original design would lead to an overly complicated production process". Participants assessed risk occurrence probability and estimated risk impact using a five-point Likert scale ( $1=$ very low; $5=$ very high), which is in line with established practices in project risk management (Raz et al. 2002).

Both estimated risk occurrence probability and estimated risk impact are formative measures, as the latent constructs are described by their indicators, and not vice versa (Diamantopoulos and Winklhofer 2001). It thus follows that an increase in the expected risk occurrence probability for one risk does not lead to an increased value for all risks. A strong correlation between the indicators of formative latent variables is not necessary; instead, we checked for 
multicollinearity. The variance inflation factor (VIF) for each item was equal to or less than 1.29, well under the recommended limit of 10 (Diamantopoulos and Winklhofer 2001).

\subsubsection{Overconfidence}

Overconfidence is commonly measured by asking participants to answer knowledge-based questions in a multiple choice format and to indicate their level of confidence in each answer. Overconfidence is present if the expectation of accuracy exceeds actual accuracy (Pulford and Colman 1997). An alternative method, which we applied for this study, requires participants to make numerical interval estimates at a given level of accuracy (McKenzie et al. 2008; Soll and Klayman 2004; Teigen and Jørgensen 2005). A confidence level of $80 \%$, for instance, thus implies that $80 \%$ of interval estimates should include the actual value. People commonly exhibit a high level of overconfidence when completing this exercise, such that less than $50 \%$ of their interval estimates contain the actual value (Moore and Healy 2008).

Interval estimates (i.e., best case and worst case estimates) at a certain level of confidence are common practice in project management (PMI 2008; Teigen and Jørgensen 2005), for instance when estimating activity durations. We therefore chose to use interval estimates to measure overconfidence, as we see this method as more closely reflecting project management practice. Project managers might not expect the generally more common measure of overconfidence based on multiple choice questions (Moore and Healy 2008) to occur in project management context. In this study, we use numerical interval estimates to measure overconfidence, but we avoided posing knowledge-based questions with numerical answers: We suspected that project managers, when asked to give interval estimates about matters that fall outside their area of competence (e.g., "How long is the Nile River?"; Moore and Healy 2008), may be reluctant to answer such requests (Kahneman and Klein 2009). We therefore decided to ask about the average completion time for a specified activity, namely, furniture assembly. Project managers often must predict how long it will take others-namely, their coworkers, subordinates, or external service providers-to complete tasks. They typically do not have to assess their own work in this manner, but rather coordinate and plan tasks to be completed by other employees. Participants estimated how long it would take, on average, to construct several pieces of IKEA furniture. Participants were asked to choose an interval range between two points - a best case and a worst case — while the actual assembly times for each piece of furniture should be within this range in $80 \%$ of the cases.

Participants based their estimates on pictorial assembly instructions that we provided to them for five pieces of furniture: a shelf, a TV stand, a stool, a stepstool, and a laundry hamper. To determine actual assembly times, we recorded the time needed for eight people (who did not participate in this study) to put together the furniture; each person assembled all five pieces independently. ${ }^{1}$ IKEA products

\footnotetext{
1 This study was not conducted in conjunction with IKEA; no support was provided by the company.
} 
were chosen because of their widespread familiarity among our sample: $95.6 \%$ of the project managers had personal experience assembling IKEA products.

Overconfidence is usually calculated by subtracting the percentage of accurate answers from the given level of confidence. When, for instance, the given confidence level is $80 \%$, and three out of five $(60 \%)$ of a participant's interval estimates include the actual furniture assembly time, the participant's overconfidence score is $\mathrm{OC}=0.8-0.6=0.2$. Anderson et al. (2012) note that scores calculated in this way may contain distortions by estimates that are fundamentally too low or too high. Following their suggestion, we therefore calculate a corrected measure of overconfidence by regressing the estimated task-completion time on the traditional calculation of overconfidence. The corrected measure of overconfidence consists of the residual scores. This overconfidence score cannot be explained by the estimated task-completion time that the participants listed for any piece of furniture, so this procedure eliminates the distorting effect. Overconfidence is decidedly not related to estimates that are too long or too short, but rather to unwarranted confidence in one's own abilities to make accurate estimates.

As expected, our exploratory factor analysis revealed only one factor. However, the results of the confirmatory factor analysis were not quite satisfying $\left(\chi^{2}=19.90\right.$, $d f=5, \chi^{2} / d f=3.98$, GFI $=0.961$, AGFI $=0.883$, RMSEA $\left.=0.121\right)$, so we excluded the laundry hamper assembly time item from our analysis, because its factor loading was only 0.529. After removing it, the confirmatory factor analysis showed mostly satisfying results $\left(\chi^{2}=5.69, d f=2, \chi^{2} / d f=2.84\right.$, GFI $=0.987$, $\mathrm{AGFI}=0.934$, RMSEA $=0.095)$. Cronbach's alpha was $0.70(\mathrm{AVE}=0.52$, $\rho=0.81)$.

\subsubsection{Risk awareness}

We use a general measure, unrelated to the case study, to assess risk awareness. Specifically, we asked project managers about the extent to which risks pose a threat to project success in project management practice.

This measure should be less sensitive to social desirability biases (Turnley and Bolino 2001) than common measures that focus on risk propensity (Sitkin and Pablo 1992; Sitkin and Weingart 1995; White et al. 2006), as project managers do not rate their own risk preference or risk-taking behavior, but instead describe their practical experience with project management. An alternative measure would have been to ask participants whether they consider their estimates to be more optimistic or pessimistic, but again we would face social desirability and self-perception biases: No experienced project manager could, for example, be expected to admit that she or he is repeatedly underestimating task-completion times or risk occurrence probabilities. The analyses relied on seven-point Likert scales $(1=$ strongly agree; 7 = strongly disagree).

The Cronbach's alpha for the six items was 0.75, which indicated good reliability. We conducted a confirmatory factor analysis for the one factor construct that did not indicate sufficiently good fit $\left(\chi^{22}=83.18, d f=9, \chi^{22} / d f=9.24\right.$, $\mathrm{GFI}=0.877$, AGFI $=0.714$, RMSEA $=0.202$ ). The exploratory factor analysis indicated the existence of two factors with three items each (44 and $19 \%$ 
explanation of total variance). We thus modeled risk awareness in a twodimensional structure as suggested by the exploratory factor analysis. We could not conduct a confirmatory factor analysis for the two-factor construct, as it was underidentified (Giere et al. 2006). We could, however, calculate the model fit for the first part of the model, which contains only the reflective constructs of overconfidence and risk awareness. The results indicate good fit $\left(\chi^{2}=36.10\right.$, $\left.d f=32, \chi^{2} / d f=1.13, \mathrm{GFI}=0.966, \mathrm{AGFI}=0.941, \mathrm{RMSEA}=0.025\right)$ and confirm risk awareness as a second-order construct with two factors. We applied this two-dimensional structure to our research model and modeled risk awareness as a second-order construct.

The first dimension appears to reflect a micro-view of risk awareness (Cronbach's $\alpha=0.65$ ). Project managers indicate if their assessment of individual risks causes problems in project management practice (for example "Unexpected problems often occur during project implementation"). The second dimension (Cronbach's $\alpha=0.72$ ) pertains to more general statements about the threat that risks pose to project success (for example "Projects usually exceed deadlines, as future developments are mostly unforeseeable"). Item elimination did not increase Cronbach's $\alpha$; therefore no items were eliminated. The average variances extracted $\left(\mathrm{AVE}_{\text {factor } 1}=0.60, \mathrm{AVE}_{\text {factor } 2}=0.65\right)$ and factor reliabilities $\left(\rho_{\text {factor } 1}=0.81\right.$, $\rho_{\text {factor } 2}=0.85$ ) exceeded the values recommended by Homburg and Baumgartner (1998).

\subsection{Modeling and avoidance of common method variance}

We calculated the model in Fig. 1 using SmartPLS (Ringle et al. 2005). We decided to use partial least squares (PLS) for this study, because it allows us to include formative variables in addition to reflective ones (Fassott and Eggert 2005). Using a case study and a specific measurement of overconfidence in our research allowed us to reduce the risk of common method variance (Podsakoff et al. 2003) by using different measurement designs for different constructs. When project managers estimated the time it would take to assemble IKEA furniture, they were not familiar with the underlying concept of overconfidence and thus did not know how the measure would be calculated. It therefore seems unlikely that project managers could match their responses to the dependent constructs or find ways to provide what they perceived to be socially desirable answers. In risk assessment, we used a substantially different design to evaluate risks compared to the dependent variable of anticipated project success; so again, participants were unlikely to be able to match their answers or anticipate a desired relationship between these two concepts. To further avoid a common method variance, we followed the suggestions of Podsakoff et al. (2003): we made participation voluntary, did not give clues about the relationships actually being examined, and guaranteed confidentiality and anonymous evaluation of the results to reduce social desirability in participants' answers. 


\section{Results}

We hypothesize in $\mathrm{H} 1$ that the estimated risk occurrence probability and the estimated risk impact would influence anticipated project success. Estimated risk occurrence probability had, in line with $\mathrm{H} 1 \mathrm{a}$, a significant impact on anticipated project success $(\gamma=-0.362, p<0.001)$. H1b, however, was rejected, as estimated risk impact did not have a significant impact on anticipated project success $(\gamma=0.026, p=0.880)$. The results are in Fig. 2; the correlations of the constructs are in Table 1.

In Hypothesis $\mathrm{H} 2$, we propose that estimated risk impact should have a significantly stronger influence on anticipated project success than estimated risk occurrence probability. Contrary to what was predicted, only the influence of estimated risk occurrence probability was found to be significant $(\gamma=-0.362, p<0.001)$, while estimated risk impact did not have significant influence $(\gamma=0.026, p=0.880)$. Furthermore, the path coefficient of estimated risk impact to anticipated project success is slightly positive, which therefore does not indicate that higher estimated risk impact would reduce anticipated project success. Using linear regression analysis, we test if estimated risk impact accounts for a significant $R^{2}$ of anticipated project success, which was not the case $\left(R^{2}=0.006, F(1202)=1.30, p=0.256\right)$. When adding estimated risk occurrence probability to the regression model, $R^{2}$ increased significantly $\left(R_{\text {change }}^{2}=0.107, F(1201)=24.17, p<0.001\right)$. Accordingly, $\mathrm{H} 2$ has to be rejected, as the results show that estimated risk impact has no significant effect on anticipated project success, while the effect of estimated risk occurrence probability on anticipated project success is significant.

To test for the mediation of risk awareness as proposed in $\mathrm{H} 3$, we first consider the path from overconfidence to the potential mediator of risk awareness: overconfidence led to significantly decreased levels of risk awareness $(\gamma=-0.178, p=0.016)$.

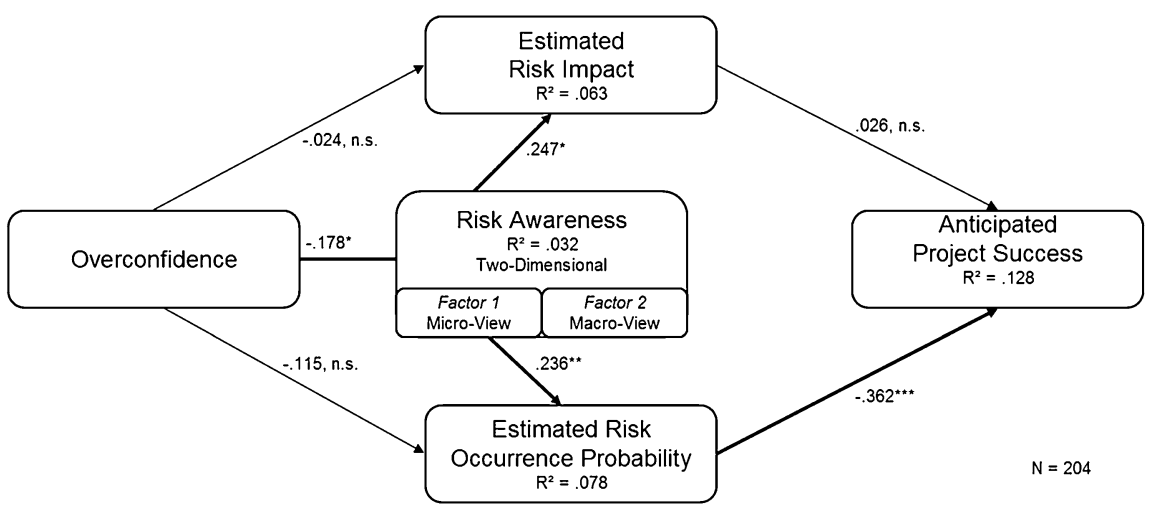

$* p<.05 ; * * p<.01 ; * * * p<.001 ;$ n.s. $=$ non significant.

${ }^{a}$ Arrows in bold indicate significant paths (two-tailed t-tests).

Fig. 2 Results 
Table 1 Correlation matrix

\begin{tabular}{|c|c|c|c|c|c|c|}
\hline Variable & $M ; \mathrm{SD}$ & $\begin{array}{l}\text { Anticipated } \\
\text { project } \\
\text { success }\end{array}$ & $\begin{array}{l}\text { Estimated } \\
\text { risk } \\
\text { impact }\end{array}$ & Overconfidence & $\begin{array}{l}\text { Risk } \\
\text { awareness }\end{array}$ & $\begin{array}{l}\text { Estimated } \\
\text { risk } \\
\text { occurrence } \\
\text { probability }\end{array}$ \\
\hline $\begin{array}{l}\text { Anticipated } \\
\text { project } \\
\text { success }\end{array}$ & $4.64 ; 1.40$ & 1 & & & & \\
\hline $\begin{array}{l}\text { Estimated risk } \\
\text { impact }\end{array}$ & $3.31 ; 0.66$ & -0.07 & 1 & & & \\
\hline Overconfidence & $0.72 ; 0.33$ & 0.03 & -0.06 & 1 & & \\
\hline Risk awareness & $5.16 ; 0.87$ & $-0.21 * *$ & $0.19 * *$ & $-0.19 * *$ & 1 & \\
\hline $\begin{array}{c}\text { Estimated risk } \\
\text { occurrence } \\
\text { probability }\end{array}$ & $3.08 ; 0.61$ & $-0.32 * *$ & 0.10 & $-0.17 *$ & $0.23 * *$ & 1 \\
\hline
\end{tabular}

Second, risk awareness significantly influenced both estimated risk occurrence probability $(\gamma=0.236, p=0.005)$ and estimated risk impact $(\gamma=0.247$, $p=0.032$ ). Excluding the risk awareness construct to assess the total effect of overconfidence on risk assessment clarified the relationship between overconfidence and both estimated risk occurrence probability (before: $\gamma=-0.115, p=0.35$; after: $\gamma=-0.143, p=0.30$ ) and estimated risk impact (before: $\gamma=-0.024, p=0.87$; after: $\gamma=-0.143, p=0.51)$. This finding indicates a mediation of risk awareness, as furthermore all path coefficients from and to the mediator are significantly different from zero (Eggert et al. 2005). To test the mediating effect, Zhao et al. (2010) suggest the bootstrapping method developed by Preacher et al. (2007). In applying this method, we found a significant indirect effect of overconfidence on risk occurrence probability through risk awareness $(p=0.039$, one-tailed), but the effect of overconfidence on estimated risk impact was only significant to a probability of error of $p<0.1$ ( $p=0.079$, one-tailed). A Sobel $z$-test (Baron and Kenny 1986) resulted in similar values: a significant indirect effect of overconfidence on risk occurrence probability ( $p=0.032$, one-tailed), but only a nearly significant effect of overconfidence on risk impact ( $p=0.063$, one-tailed). We did not uncover a significant, direct impact of overconfidence on estimated risk occurrence probability $(\gamma=-0.115$, $p=0.345)$; we therefore cannot confirm H4a. Similarly, we were not able to uncover a significant, direct impact of overconfidence on estimated risk impact $(\gamma=-0.024$, $p=0.867$ ), we thus cannot confirm H4b.

We gathered demographic data about the participants (gender, age, education, project management experience, and certification) to control for the potential effects of these variables. Only age exerted an effect: a significant negative impact on estimated risk occurrence probability $\left(\gamma=-0.306, p<0.001, R^{2}=0.093\right)$. It did not, however, influence estimated risk impact. We performed an ANOVA to test for a gender effect on overconfidence, but did not find any significant effect $[F(1,202)=0.083, p=0.773]$. 
Moreover, overconfidence did not depend on age $\left(r_{s}=0.043, p=0.545\right)$ or project management experience $\left(r_{s}=0.049, p=0.483\right)$, while higher education might reduce overconfidence $\left(r_{s}=-0.106, p=0.132\right)$.

Just as in other professions, project managers as a group demonstrate a significant level of overconfidence: Their estimates did not achieve the intended confidence level of $80 \%$ certainty. Instead, they contained the empirically determined furniture assembly times in only $26.5 \%$ of the cases. This value demonstrates the severity with which project managers overestimate their accuracy in making project-related estimates.

\section{Discussion and conclusions}

\subsection{Discussion of findings and implications}

A high percentage of projects fail to comply with project objectives (Huff and Prybutok 2008; Shepherd and Cardon 2009; Whittaker 1999). Such deviations from the project management plan are predominantly caused by risks, i.e., uncertain events or conditions that, if they occur, have a positive or negative effect on a project's objectives (Bryde and Volm 2009; PMI 2008). Thus, we concluded that occurrence probability of risks and their potential impact on project objectives may be insufficiently reflected in anticipated project success, as otherwise, such deviations would not occur as frequently.

This study investigated the influence of project managers' risk assessment on anticipated project success and found-contrary to what we proposed in $\mathrm{H} 2$ - that project managers only consider risk occurrence probabilities, but neglect potential risk impacts on project objectives. According to the priority heuristic (Brandstätter et al. 2006; Brandstätter and Gussmack 2013; Glöckner and Betsch 2008), a focus on outcomes rather than on occurrence probabilities would have been expected. Furthermore, according to expected utility models such as the prospect theory (Kahneman and Tversky 1979; Tversky and Kahneman 1992), individuals would calculate the utility of a risky decision based on both potential outcomes and the respective probabilities of such outcomes. Thus, our results support neither prospect theory nor the priority heuristic in the given research context; instead, our results indicate that managers consider the likelihood of risks arising when evaluating potential project success while neglecting risk impacts. Future research may help to clarify under which circumstances project managers mainly consider risk occurrence probabilities when anticipating project success. A replication of this finding and the introduction of additional control variables (beyond demographic data) may be required to detect opportunities to refine decision theory. Project management needs to address risk impact explicitly in the decision-making processes. It is therefore necessary to include both risk impact and risk occurrence probability in the risk analysis, as suggested by PMI (2008). However, even with both elements included, project managers are likely only to consider risk occurrence probability when assessing how successful a project will be. Their biased assessment of anticipated project success could be mitigated by an expected monetary value analysis (PMI 2008), which entails both risk impacts and probabilities; although 
with this method, people may just assume that negative scenarios linked to highimpact risks are less likely to occur than they actually are (Newby-Clark et al. 2000). The threat posed by these biased assessments of project success is not easy to address in project management practice; risk impact is formally assessed in most projects, and project managers may assume that risk impact has been appropriately considered during the project-related decision process. But in reality, risk impact may never have actually impacted their predictions of project success, in that it had no actual influence on the decision-making process.

The average project manager has a strong tendency toward overconfident judgments. This means that planning deviations are likely, because overconfidence leads project managers to assume that deviations from their planning figures are less likely than they actually are. When making two-point estimates at a given level of confidence, this level is rarely achieved; for our study, the target confidence level was $80 \%$ certainty, but our empirically determined furniture assembly times were only included in $26.5 \%$ of the estimations. To reduce threats to project objectives, effective risk management needs to be established to identify risks and plan responses in advance. If this is not possible, risk management methods should be used to reduce the impact of unexpected risks by developing solutions to get the project back on track (PMI 2008).

Project managers with higher levels of overconfidence also demonstrate lower levels of risk awareness, so they are likely to expend less effort to identify risks, conduct quantitative or qualitative risk analyses, and design appropriate solutions should a risk occur (Bryde and Volm 2009; Huff and Prybutok 2008). An overconfident project manager expects a project to be implemented successfully without deviating from what is planned. This low risk awareness may result in a reduction in the perceived need to undertake sophisticated project risk management, which further increases the threat of risks to project success. Risk awareness acts as a mediator between overconfidence and risk assessment. Older project managers assessed project risk occurrence probability as significantly less high, such that they planned more optimistically than their younger colleagues, independently of their amount of project management experience.

\subsection{Limitations and further research}

Estimated risk impact and estimated risk occurrence probability account only for a limited proportion of the variance in anticipated project success $(12.8 \%)$. It would be desirable to identify additional determinants that might explain when or why project managers expect a project to be carried out successfully. For example, perhaps comparative optimism, or the "better than average" effect, may increase managers' expectations of success for their own projects (Hoorens et al. 2008; Krizan and Windschitl 2007). Overconfidence influences project managers' risk assessments through their risk awareness; therefore, it may be helpful to identify additional determinants of risk awareness and risk assessment to understand when managers tend to underestimate risk occurrence probabilities and risk impacts. As risks may have positive or negative effects on project's objectives (Bryde and Volm 2009; Maguire and Hardy 2013; PMI 2008), it may also be beneficial for future research not only to 
include risks with predominantly negative or undesirable consequences, but also to consider risks which may create opportunities for the company.

Our results identify risk awareness as a mediator between overconfidence and risk assessment. The availability heuristic (Schwarz et al. 1991; Tversky and Kahneman 1973) might explain why overconfident project managers perceive risks as less threatening: Overconfidence might reduce the availability of risks in project managers' memories, and this lower availability of risks decreases the perceived threat of those risks (Pachur et al. 2012). However, in the present study, we did not assess the availability of risks, but only risk awareness as the generic attitude of people toward the threats to project success posed by project risks. Assessing the availability of risks together with overconfidence could advance the understanding of overconfidence by clarifying whether overconfidence indeed reduces the availability of risks in memory. When the availability of risks in project managers' memories is low, they will find it harder to recall occasions in which risks occurred. This would reduce the estimated risk occurrence probabilities, as availability heuristic suggests that people base their likelihood estimates on the availability of events in memory (Schwarz et al. 1991; Tversky and Kahneman 1973). We see a research opportunity in evaluating the statement of Van Zant and Moore (2013) in detail, claiming that overconfidence can blind people to the size of the risks they are taking. Future research may investigate whether overconfidence reduces the availability of risks, therefore 'blinding' people to the threat posed by said risks.

A limitation of our study stems from its setting. Although we used a case study and measures related to project management, it is not possible to replicate the full complexity and scope of a real project in a laboratory setting. For example, interactions among different individuals involved in the project likely exert effects that we did not measure. People involved in the project may have different risk perceptions due to their organizational roles. For instance, an assigned "risk response owner" who has "responsibility for each agreed-to and funded risk response" (PMI 2008, 301) might perceive a particular risk in their area of responsibility as more threatening to project objectives than other risks. A project member concerned with quality management will focus on different risks than a team member whose focus is project communications or human resources. Similarly, a project manager likely perceives risks and project success differently than other internal or external stakeholders, but will still be influenced by these stakeholders through the communication they undertake to form an agreement on project objectives and to promote an accurate understanding of project benefits and risks.

Finally, we used a cross-sectional data set and thus have no information about developments of anticipated project success or overconfidence over time, from project initialization to subsequent phases of implementation and completion. The project managers who participated in our study also have different professional backgrounds, representing various industries and companies. Perhaps project managers in IT companies behave differently from project managers in the building sector, who may behave differently from project managers focused on new product development or machinery development, for example. However, we found no indication that project managers from different industries exhibited different planning behavior in our study. 


\subsection{Conclusion}

Estimates of risk impact-unlike risk occurrence probability-appear insufficiently considered when project managers form expectations about project success. Therefore, and especially for high-impact risks, risk management efforts should focus on planning risk responses to reduce their potential impact, should such risks occur. The finding that project managers do not consider estimated risk impact-the consequences of which are linked directly to project outcomes-in anticipated project success is different from what decision theory would predict. Future research may help to clarify why only risk occurrence probability is considered when anticipating project success. This finding - that project risks are inadequately considered in anticipated project success - is of crucial importance for project management, as it offers an explanation as to why so many projects fail, i.e., do not comply with predefined budgets, time constraints, or product scope and quality. Overconfidence leads project managers through the mediator of risk awareness, to assess estimated risk occurrence probability and estimated risk impact more optimistically. The mediation through risk awareness indicates that overconfidence may be linked to the reduced availability of risks, which leads to risks being perceived as non-threatening and unlikely to occur. Such biased risk assessment may lead companies to start seemingly beneficial projects which later show an unfavorable benefit-cost ratio, indicating that they should have never been undertaken in the first place.

Open Access This article is distributed under the terms of the Creative Commons Attribution 4.0 International License (http://creativecommons.org/licenses/by/4.0/), which permits unrestricted use, distribution, and reproduction in any medium, provided you give appropriate credit to the original author(s) and the source, provide a link to the Creative Commons license, and indicate if changes were made.

\section{Appendix}

See Figs. 3 and 4.

\begin{tabular}{|c|c|c|c|}
\hline Marketing & $\begin{array}{l}\text { Controlling } I \\
\text { Finance }\end{array}$ & $\begin{array}{l}\text { Research \& } \\
\text { Development }\end{array}$ & Production \\
\hline $\begin{array}{l}\text { Perform } \\
\text { Market Analysis }\end{array}$ & Commercial Analysis & $\begin{array}{l}\text { Develop } \\
\text { Prototype }\end{array}$ & $\begin{array}{l}\text { Determine } \\
\text { Production Process }\end{array}$ \\
\hline $\begin{array}{l}\text { Analyze } \\
\text { Competitors' Products }\end{array}$ & $\begin{array}{l}\text { Calculate } \\
\text { Return-On-Investment }\end{array}$ & $\begin{array}{l}\text { Specify } \\
\text { Technical Parameters }\end{array}$ & $\begin{array}{l}\text { Determine Steps of the } \\
\text { Production Process }\end{array}$ \\
\hline $\begin{array}{l}\text { Determine } \\
\text { Customer Needs }\end{array}$ & $\begin{array}{l}\text { Conduct } \\
\text { Break-Even-Analysis }\end{array}$ & $\begin{array}{l}\text { Build a } \\
\text { Prototype }\end{array}$ & Perform Test-Run \\
\hline $\begin{array}{l}\text { Create } \\
\text { Product Design }\end{array}$ & & $\begin{array}{l}\text { Test the } \\
\text { Prototype }\end{array}$ & \\
\hline $\begin{array}{l}\text { Collect and } \\
\text { Evalute Ideas }\end{array}$ & & $\begin{array}{l}\text { Test } \\
\text { Product Safety }\end{array}$ & \\
\hline Create Sketches & & $\begin{array}{l}\text { Test } \\
\text { Customer Acceptance }\end{array}$ & \\
\hline
\end{tabular}

Fig. 3 Example of work breakdown structure 
Technical Feasibility:

Within the last years around $40 \%$ of the newly developed products had to be changed in order to fit technical requirements. Designs are changed for instance when the original design would lead to an overly complicated production process.

\begin{tabular}{l}
$\begin{array}{l}\text { very low } \\
\text { The design of the product has to be changed } \\
\text { in order to ensure technical feasibility. }\end{array}$ \\
\hline
\end{tabular}

Potential customer's product evaluation

Around three out of ten newly developed products are changed due to critique from potential customers testing the prototype prior to market release.

\begin{tabular}{|llllll} 
& very low & Occurrence Probabilty & visk Impact & very high \\
\hline $\begin{array}{l}\text { Potential customers testing the prototype } \\
\text { suggest remodeling the design. }\end{array}$ & 0 & very low & & 0
\end{tabular}

Production process:

The first test-run is not successful in around $50 \%$ of the cases.

\begin{tabular}{l}
$\begin{array}{l}\text { Additional test-runs are required as } \\
\text { the first test-run is not successful. }\end{array}$ \\
\hline
\end{tabular}

Functionalities of the prototype:

All wooden toys include more or less sophisticated functionalities; sometimes small cable pulls are used. These mechanisms sometimes do not work to full satisfaction for prototypes.

very low
The functionality of the prototype
is lacking.

Project team of the R\&D department:

The project team is now working together as a team for the first time. All team members know each other well.

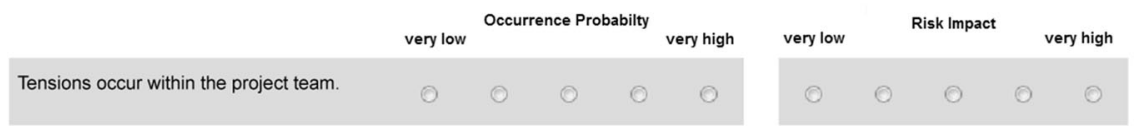

Fig. 4 Risk assessment

\section{References}

Anderson, C., S. Brion, D.A. Moore, and J.A. Kennedy. 2012. A status-enhancement account of overconfidence. Journal of Personality and Social Psychology 103: 718-735.

Barber, S.J., R. Gordon, and N. Franklin. 2009. Self-relevance and wishful thinking: facilitation and distortion in source monitoring. Memory and Cognition 37: 434-446.

Barber, B.M., and T. Odean. 2001. Boys will be boys: overconfidence, and common stock investment. The Quarterly Journal of Economics 116: 261-292.

Baron, R.M., and D.A. Kenny. 1986. Moderator-mediator variables distinction in social psychological research: conceptual, strategic, and statistical considerations. Journal of Personality and Social Psychology 51: 1173-1182. 
Brandstätter, E., G. Gigerenzer, and R. Hertwig. 2006. The priority heuristic: making choices without trade-offs. Psychological Review 113: 409-432.

Brandstätter, E., and M. Gussmack. 2013. The cognitive processes underlying risky choices. Journal of Behavioral Decision Making 26: 185-197.

Bingham, C.B., and K.M. Eisenhardt. 2011. Rational heuristics: the 'simple rules' that strategists learn from process experience. Strategic Management Journal 32: 1437-1464.

Brockman, B.K., M.A. Jones, and R.C. Becherer. 2012. Customer orientation and performance in small firms: examining the moderating influence of risk-taking, innovativeness, and opportunity focus. Journal of Small Business Management 50: 429-446.

Bryde, D.J., and J.M. Volm. 2009. Perceptions of owners in German construction projects: congruence with project risk theory. Construction Management and Economics 27: 1059-1071.

Buehler, R., D. Griffin, and M. Ross. 1994. Exploring the "planning fallacy": why people underestimate their task completion times. Journal of Personality and Social Psychology 67: 366-381.

Busenitz, L.W., and J.B. Barney. 1997. Differences between entrepreneurs and managers in large organizations: biases and heuristics in strategic decision-making. Journal of Business Venturing 12: 9-30.

Cooper, T., and A. Faseruk. 2011. Strategic risk, risk perception and risk behaviour: meta-analysis. Journal of Financial Management and Analysis 24: 20-29.

Dey, P.K. 2012. Project risk management using multiple criteria decision-making technique and decision tree analysis: a case study of Indian oil refinery. Production Planning and Control 23: 903-921.

Diamantopoulos, A., and H.M. Winklhofer. 2001. Index construction with formative indicators: an alternative to scale development. Journal of Marketing Research 38: 269-277.

Eggert, A., G. Fassott, and S. Helm. 2005. Identifizierung und Quantifizierung mediierender und moderierender Effekte in komplexen Kausalstrukturen. In Handbuch PLS-PfadmodellierungMethode, ed. F. Bliemel, A. Eggert, and J. Henseler, 101-116. Stuttgart: Anwendung, Praxisbeispiele.

Fassott, G., and A. Eggert. 2005. Zur Verwendung formativer und reflektiver Indikatoren in Strukturgleichungsmodellen: Bestandsaufnahme und Anwendungsempfehlungen. In Handbuch PLS-Pfadmodellierung-Methode, ed. F. Bliemel, A. Eggert, and J. Henseler, 31-47. Stuttgart: Anwendung, Praxisbeispiele.

Finucane, M.L., A. Alhakami, P. Slovic, and S.M. Johnson. 2000. The affect heuristic in judgments of risks and benefits. Journal of Behavioral Decision Making 13: 1-17.

Giere, J., B.W. Wirtz, and O. Schilke. 2006. Mehrdimensionale Konstrukte. Die Betriebswirtschaft 66: $678-695$.

Gigerenzer, G., and H. Brighton. 2009. Homo heuristicus: why biased minds make better inferences. Topics in Cognitive Science 1: 107-143.

Glöckner, A., and T. Betsch. 2008. Do people make decisions under risk based on ignorance? An empirical test of the priority heuristic against cumulative prospect theory. Organizational Behavior and Human Decision Processes 107: 75-95.

Goodman, J.K., and J.R. Irwin. 2006. Special random numbers: beyond the illusion of control. Organizational Behavior and Human Decision Processes 99: 161-174.

Gordon, R., N. Franklin, and J. Beck. 2005. Wishful thinking and source monitoring. Memory and Cognition 33: 418-429.

Handelsblatt (2015) Aufsichtsrat will mehr Steuergeld für die Finanzierung. http://www.handelsblatt. com/unternehmen/handel-konsumgueter/hauptstadtflughafen-aufsichtsrat-will-mehr-steuergeldfuer-die-finanzierung/11503168.html. Accessed 01 Apr 2015.

Hayward, M.L.A., D.A. Shepherd, and D. Griffin. 2006. A hubris theory of entrepreneurship. Management Science 52: 160-172.

Hertwig, R., T. Pachur, and S. Kurzenhäuser. 2005. Judgments of risk frequencies: tests of possible cognitive mechanisms. Journal of Experimental Psychology. Learning, Memory, and Cognition 31: 621-642.

Homburg, C., and H. Baumgartner. 1998. Beurteilung von Kausalmodellen-Bestandsaufnahme und Handlungsempfehlungen. In Die Kausalanalyse-Ein Instrument der empirischen betriebswirtschaftlichen Forschung, ed. L. Hildebrandt, and C. Homburg, 343-369. Stuttgart: SchäfferPoeschel.

Hoorens, V., T. Smits, and J.A. Shepperd. 2008. Comparative optimism in the spontaneous generation of future life-events. British Journal of Social Psychology 47: 441-451. 
Huff, R.A., and V.R. Prybutok. 2008. Information systems project management decision making: the influence of experience and risk propensity. Project Management Journal 39: 34-47.

Hutchinson, J.M.C., and G. Gigerenzer. 2005. Simple heuristics and rules of thumb: where psychologists and behavioural biologists might meet. Behavioural Processes 69: 97-124.

Ika, L.A. 2009. Project success as a topic in project management journals. Project Management Journal 40(4): 6-19.

Jørgensen, M. 2004. Realism in assessment of effort estimation uncertainty: it matters how you ask. IEEE Transactions on Software Engineering 30: 209-217.

Jugdev, K., and R. Müller. 2005. A retrospective look at our evolving understanding of project success. Project Management Journal 36(4): 19-31.

Kahneman, D., and G. Klein. 2009. Conditions for intuitive expertise: a failure to disagree. American Psychologist 64(6): 515-526.

Kahneman, D., and A. Tversky. 1979. Prospect theory: an analysis of decision under risk. Econometrica 47: 263-291.

Kahneman, D., and A. Tversky. 1996. On the reality of cognitive illusions. Psychological Review 103: 582-591.

Karmarkar, U.S., and R.C. Pitbladdo. 1997. Quality, class, and competition. Management Science 43: 27-39.

King, J., and P. Slovic. 2014. The affect heuristic in early judgments of product innovations. Journal of Consumer Behaviour 13: 411-428.

Krizan, Z., and P.D. Windschitl. 2007. The influence of outcome desirability on optimism. Psychological Bulletin 133: 95-121.

Langer, E.J., and J. Roth. 1975. Heads I win, tails it's chance: the illusion of control as a function of the sequence of outcomes in a purely chance task. Journal of Personality and Social Psychology 32: 951-955.

Li, J., and Y. Tang. 2010. CEO hubris and firm risk taking in China: the moderating role of managerial descretion. Academy of Management Journal 53: 45-68.

Maguire, S., and C. Hardy. 2013. Organizing processes and the construction of risk: a discursive approach. Academy of Management Journal 58: 231-255.

Malmendier, U., and G. Tate. 2008. Who makes acquisitions? CEO overconfidence and the market's reaction. Journal of Financial Economics 89: 20-43.

Marmier, F., D. Gourc, and F. Laarz. 2013. A risk oriented model to assess strategic decisions in new product development projects. Decision Support Systems 56: 74-82.

McKenzie, C.R.M., M.J. Liersch, and I. Yanic. 2008. Overconfidence in interval estimates: what does expertise buy you? Organizational Behavior and Human Decision Processes 107: 179-191.

Moore, D.A., and P.J. Healy. 2008. The trouble with overconfidence. Psychological Review 115: 502-517.

Newby-Clark, I.R., M. Ross, R. Buehler, D.J. Koehler, and D. Griffin. 2000. People focus on optimistic scenarios and disregard pessimistic scenarios while predicting task completion times. Journal of Experimental Psychology: Applied 6: 171-182.

Nicolai, A., and A. Kieser. 2002. Trotz eklatanter Erfolglosigkeit: die Erfolgsfaktorenforschung weiter auf Erfolgskurs. Die Betriebswirtschaft 62: 579-596.

Nosić, A., and M. Weber. 2010. How riskily do I invest? The role of risk attitudes, risk perception, and overconfidence. Decision Analysis 7: 282-301.

Oehmen, J., A. Olechowski, R. Kenley, and M. Ben-Daya. 2014. Analysis of the effect of risk management practices on the performance of new product development programs. Technovation. 34: 441-453.

Pachur, T., R. Hertwig, and F. Steinmann. 2012. How do people judge risks: availability heuristic, affect heuristic, or both? Journal of Experimental Psychology: Applied 18: 314-330.

Pich, M.T., C.H. Loch, and A. De Meyer. 2002. On uncertainty, ambiguity, and complexity in project management. Management Science 48: 1008-1023.

PMI. 2008. A guide to the project management body of knowledge, 4th ed. Newtown Square: Project Management Institute.

Podsakoff, P.M., S.B. MacKenzie, J.Y. Lee, and N.P. Podakoff. 2003. Common method biases in behavioral research: a critical review of the literature and recommended remedies. Journal of Applied Psychology 88: 879-903.

Preacher, K.J., D.D. Rucker, and A.F. Hayes. 2007. Addressing moderated mediation hypotheses: theory, methods, and prescriptions. Multivariate Behavioral Research 42: 185-227. 
Press Release Airport Berlin-Brandenburg (2004) Aufsichtsrat gibt grünes Licht für BBI-Finanzierungskonzept (10.12.2004). http://preview.berlin-airport.de/de/presse/pressemitteilungen/ 2004/2004-12-10-gruenes-licht/index.php. Accessed 01 Sept 2013.

Pulford, B.D., and A.M. Colman. 1997. Overconfidence: feedback and item difficulty effects. Personality and Individual Differences 23: 125-133.

Raz, T., A.J. Shenhar, and D. Dvir. 2002. Risk management, project success, and technological uncertainty. R\&D Management 32: 101-109.

Ringle, C.M., S. Wende, and A. Will. 2005. Smart PLS. Germany: Hamburg.

Salomo, S., J. Weise, and H.G. Gemünden. 2007. NPD planning activities and innovation performance: the mediating role of process management and the moderating effect of product innovativeness. Journal of Product Innovation Management 24: 285-302.

Schwarz, N., H. Bless, F. Strack, G. Klumpp, H. Rittenauer-Schatka, and A. Simons. 1991. Ease of retreival as information: another look at the availability heuristic. Journal of Personality and Social Psychology 61: 195-202.

Seybert, N., and R. Bloomfield. 2009. Contagion of wishful thinking in markets. Management Science 55: 738-751.

Shepherd, D.A., and M.S. Cardon. 2009. Negative emotional reactions to project failure and the selfcompassion to learn from the experience. Journal of Management Studies 46: 923-949.

Shepherd, D.A., H. Patzelt, and M. Wolfe. 2011. Moving forward from project failure: negative emotions, affective commitment, and learning from experience. Academy of Management Journal 54: 1229-1259.

Simon, M., and S.M. Houghton. 2003. The relationship between overconfidence and the introduction of risky products: evidence from a field study. Academy of Management Journal 46: 139-149.

Sitkin, S.B., and A.L. Pablo. 1992. Reconceptualizing the determinants of risk behavior. Academy of Management Review 17: 9-38.

Sitkin, S.B., and L.R. Weingart. 1995. Determinants of risky decision-making behavior: a test of the mediating role of risk perceptions and propensity. Academy of Management Journal 38: 1573-1592.

Sjöberg, L., and E. Engelberg. 2010. Risk perception and movies: a study of availability as a factor in risk perception. Risk Analysis 30: 95-106.

Slovic, P., M.L. Finucane, E. Peters, and D.G. MacGregor. 2007. The affect heuristic. European Journal of Operational Research 177: 1333-1352.

Soll, J.B., and J. Klayman. 2004. Overconfidence in interval estimates. Journal of Experimental Psychology. Learning, Memory, and Cognition 30: 299-314.

Speirs-Bridge, A., F. Fidler, M. McBride, L. Flander, G. Cumming, and M. Burgman. 2010. Reducing overconfidence in the interval judgments of experts. Risk Analysis: An International Journal 30: $512-523$.

Teigen, K.H., and M. Jørgensen. 2005. When $90 \%$ confidence intervals are 50\% certain: on the credibility of credible intervals. Applied Cognitive Psychology 19: 455-475.

Teller, J., A. Kock, and H.G. Gemünden. 2014. Risk management in project portfolios is more than managing project risks: a contingency perspective on risk management. Project Management Journal. 45: 67-80.

Tsai, C.I., J. Klayman, and R. Hastie. 2008. Effects of amount of information on judgment accuracy and confidence. Organizational Behavior and Human Decision Processes 107: 97-105.

Turnley, W.H., and M.C. Bolino. 2001. Achieving desired images while avoiding undesired images: exploring the role of self-monitoring in impression management. Journal of Applied Psychology 86: 351-360.

Tversky, A., and D. Kahneman. 1973. Availability: a heuristic for judging frequency and probability. Cognitive Psychology 5: 207-232.

Tversky, A., and D. Kahneman. 1992. Advances in prospect theory: cumulative representation of uncertainty. Journal of Risk and Uncertainty 5: 297-323.

Van Zant, A.B., and D.A. Moore. 2013. Avoiding the pitfalls of overconfidence while benefiting from the advantages of confidence. California Management Review 55(2): 5-23.

Vosgerau, J. 2010. How prevalent is wishful thinking? Misattribution of arousal causes optimism and pessimism in subjective probabilities. Journal of Experimental Psychology 139: 32-48.

White, R.E., S. Thornhill, and E. Hampson. 2006. Entrepreneurs and evolutionary biology: the relationship between testosterone and new venture creation. Organizational Behavior and Human Decision Processes 100: 21-34. 
Whittaker, B. 1999. What went wrong? Unsuccessful information technology projects. Information Management and Computer Security 7: 23-29.

Windschitl, P.D., A.R. Smith, J.P. Rose, and Z. Krizan. 2010. The desirability bias in predictions: going optimistic without leaving realism. Organizational Behavior and Human Decision Processes 111: $33-47$.

Zhao, X., J.G. Lynch Jr, and Q. Chen. 2010. Reconsidering Baron and Kenny: myths and truths about mediation analysis. Journal of Consumer Research 37: 197-206. 